\title{
Predictors of breastfeeding initiation in Hong Kong and Mainland China born mothers
}

\author{
Kris Yuet Wan Lok, Dorothy Li Bai and Marie Tarrant ${ }^{*}$
}

\begin{abstract}
Background: In recent years there has been a steady influx of immigrants into Hong Kong from Mainland China, where breastfeeding patterns differ. Studies in other regions have found substantial differences in breastfeeding rates between native-born and immigrant mothers. The purpose of this study was to examine factors associated with breastfeeding initiation in Hong Kong born and Mainland China born mothers living in Hong Kong.
\end{abstract}

Methods: We used a multi-center cross-sectional study design and recruited 2761 new mothers from the postnatal wards of all eight public hospitals in Hong Kong that offer obstetric services. We assessed breastfeeding status as well as various socio-demographic, maternal and birth characteristics. Chi-square tests and multivariable logistic regression were used to identify the predictors of breastfeeding initiation in Hong Kong born and Mainland China born participants.

Results: $80.3 \%$ of Hong Kong and $81.1 \%$ of Mainland Chinese born women initiated breastfeeding. In the fully adjusted models, multiparity (Odds Ratio [OR] 0.53, $95 \% \mathrm{Cl} 0.43-0.66$ ) and maternal smoking (OR 0.29, $95 \% \mathrm{Cl} 0.18-0.45$ ) were strongly associated with failure to initiate breastfeeding in both Hong Kong and Mainland China born participants. In Hong Kong born mothers, participants with lower maternal education and those who had a cesarean section were significantly less likely to breastfeed. For Mainland China born mothers, paternal smoking (OR 0.70, $95 \% \mathrm{Cl}$ 0.49-0.99) and having a pregnancy-related health problem $(\mathrm{OR} 0.60,95 \% \mathrm{Cl} 0.38-0.94)$ were both additional risk factors for not breastfeeding.

Conclusion: This study has identified predictors of breastfeeding initiation in Hong Kong and Mainland China born mothers. Given the current high breastfeeding initiation rates among both groups, antenatal breastfeeding education and promotion programmes need to specifically intervene with sub-groups of pregnant women at risk for not breastfeeding so that their efforts are more strategic and cost-effective.

Keywords: Breastfeeding, Initiation, Chinese, Hong Kong

\section{Background}

The benefits of breastfeeding have been widely recognized in both developing and industrialized countries [1]. International health organizations recommend exclusive breastfeeding for the first six months of life with breastfeeding maintained as an integral part of the infant's diet for one to two years of age and beyond $[1,2]$. Globally, there is an increasing trend of mothers initiating breastfeeding [3], although rates of exclusive breastfeeding remain low and

\footnotetext{
* Correspondence: tarrantm@hku.hk

School of Nursing, Li Ka Shing Faculty of Medicine, University of Hong Kong, 21 Sassoon Road, Pokfulam, Hong Kong SAR
}

overall duration is short [4-10]. When compared with infant formula feeding, breastfeeding provides unparalleled health benefits to both the infant and the mother. Breastfeeding infants have lower rates of most infectious diseases [11], fewer infectious disease hospitalizations [12-14], and more stable growth trajectories [15]. In the early postpartum period breastfeeding reduces the mother's risk of postpartum hemorrhage and in the long-term reduces the risk of both breast and ovarian cancers [16, 17].

Over the past 30 years, breastfeeding initiation rates in Hong Kong have increased from $19 \%$ in 1981 [18] to over $85 \%$ in 2012 [19]. Studies in other populations have found 
several factors associated with breastfeeding initiation, such as older maternal age [20,21], higher education $[10,22,23]$, and higher socioeconomic status [10, 24]. A large-scale population-based Hong Kong birth cohort study conducted in 1997 found similar patterns of breastfeeding initiation, whereby older maternal age and higher education were positively associated with breastfeeding initiation [25]. However, studies of breastfeeding continuation in Hong Kong have found that less educated, lower income and migrant mothers tend to continue breastfeeding for longer periods [26, 27]. Moreover, in recent years, there has been a steady influx of immigrants to Hong Kong from Mainland China $[28,29]$. Breastfeeding rates in China have generally been higher than that of Hong Kong [30]. Studies outside of Asia have found that breastfeeding initiation rates differ substantially with ethnicity [31-33]. In the United States (US) Caucasian women initiate breastfeeding at higher rates than Non-Caucasian women [32, 34]. In Hong Kong, there have been few highquality population-based studies looking at breastfeeding initiation rates and patterns. Furthermore, few studies have compared breastfeeding initiation rates between Hong Kong born and Mainland Chinese born mothers. Although both groups are ethnically Chinese, there are substantial socio-cultural differences between Hong Kong born women and women who have migrated from Mainland China [28]. Given the rapidly changing demographic makeup of the Hong Kong population due to substantial inward migration, it is important to further examine factors associated with breastfeeding initiation between these two groups to better target breastfeeding promotion efforts and to improve breastfeeding outcomes. Thus, the aim of this study was to examine and compare factors associated with breastfeeding initiation in Hong Kong and Mainland China born mothers living in Hong Kong.

\section{Methods}

\section{Design, setting and participants}

Participants were drawn from a territory wide crosssectional study conducted at all eight public hospitals with in-patient postnatal obstetric services in Hong Kong from April to June 2011. The detailed study methodology is described in detail elsewhere [35]. Briefly, we recruited Chinese-speaking mothers who had just given birth to a live newborn, and who were at least 18 years of age and Hong Kong residents. In Hong Kong, eight public and ten private hospitals offer obstetric services, with public hospitals accounting for over two-thirds of all births to Hong Kong residents [36]. During the postpartum stay, demographic data were collected by maternal self-report using a self-administered questionnaire. A trained research nurse collected the relevant maternal, obstetric, and birth data directly from participants. Breastfeeding initiation was defined as the infant having received human milk at least once during the hospital stay prior to participant recruitment. Breastfeeding status was ascertained from the inpatient log sheet on the postnatal ward and validated with the participants. Study findings are reproted in accordance with the STROBE statement [37].

\section{Data analysis}

Chi-square statistics were used to compare the characteristics of the sample and to assess the maternal and infant characteristics associated with breastfeeding initiation in Hong Kong and Mainland China born women. Multivariable logistic regression analyses were performed to estimate the unadjusted and fully adjusted associations between the study variables and breastfeeding initiation. All variables were entered into the multivariable logistic regression models and odds ratios with $95 \%$ confidence intervals were computed. The Hosmer-Lemeshow test [38] was used to assess the fit of the logistic regression models. The 0.05 level of significance was used throughout the statistical analysis and all data analysis was conducted using Stata version 13.1 statistical software (Stata Corp, College Station, Tx) [39].

\section{Ethics}

Ethical approval for the study was obtained from the Institutional Review Board of the University of Hong Kong/ Hospital Authority Hong Kong West Cluster and from all participating hospitals. All participants gave informed written consent.

\section{Results}

Of 3487 postpartum mothers approached, 2863 agreed to participate in the study. Subsequently, 36 participants were excluded because of failure to complete the data collection forms, leaving 2827 participants with complete data (Site $A=221$; Site $B=211$; Site $C=305$; Site $D=308$; Site $E=431$; Site $F=419$; Site $G=544$; Site $H=388$ ). Six study hospitals provided us with birth statistics for the study period, from which we have estimated that the recruited participants captured between 50 and $60 \%$ of all eligible pregnant women in the public hospitals during the study period. Among the 2827 participants, 2761 were eligible for this analysis based on their birthplace of either Hong Kong $(n=1757)$ or Mainland China $(n=1004)$. A total of $80.6 \%(n=2225)$ of participants initiated breastfeeding in the hospital, with similar rates among Hong Kong born mothers $(80.3 \%)$ and Mainland China born mothers (81.1\%).

The characteristics of the participants are presented in Table 1. Overall, the majority of the participants were aged 30 years or over (64.6\%), married (94.2\%), non-smokers (96.6\%), and without any pre-existing health conditions $(91.5 \%)$ or pregnancy-related complications $(86.5 \%)$. The majority of births were vaginal deliveries (73.9 \%) with 
Table 1 Characteristics of the sample

\begin{tabular}{|c|c|c|c|c|}
\hline & $\begin{array}{l}\text { All subjects } \\
(N=2761)\end{array}$ & $\begin{array}{l}\text { Hong Kong Chinese born } \\
(N=1757)\end{array}$ & $\begin{array}{l}\text { Mainland China born women } \\
(N=1004)\end{array}$ & $P$ value \\
\hline Initiated breastfeeding & & & & 0.623 \\
\hline Yes & $2225(80.6)$ & $1411(80.3)$ & $814(81.1)$ & \\
\hline No & $536(19.4)$ & $346(19.7)$ & $190(18.9)$ & \\
\hline Maternal age (years) & & & & 0.001 \\
\hline $18-24$ & $265(9.6)$ & $159(9.1)$ & $106(10.6)$ & \\
\hline $25-29$ & $712(25.8)$ & $419(23.9)$ & $293(29.2)$ & \\
\hline $30-34$ & $1028(37.2)$ & $697(39.7)$ & $331(33.0)$ & \\
\hline$\geq 35$ & $756(27.4)$ & $482(27.4)$ & $274(27.3)$ & \\
\hline Parity & & & & $<0.001$ \\
\hline Primiparous & $1470(53.2)$ & $1043(59.4)$ & $427(42.5)$ & \\
\hline Multiparous & $1291(46.8)$ & 714 (40.6) & $577(57.5)$ & \\
\hline Maternal education & & & & $<0.001$ \\
\hline Compulsory secondary or below ${ }^{a}$ & $1662(60.2)$ & $949(54.0)$ & $713(71.0)$ & \\
\hline Upper secondary & $486(17.6)$ & $323(18.4)$ & $163(16.2)$ & \\
\hline University degree or above & $613(22.2)$ & $485(27.6)$ & $128(12.8)$ & \\
\hline Monthly family income $(H K D)^{b}$ & & & & $<0.001$ \\
\hline$<\$ 15,000$ & $692(25.1)$ & $269(15.3)$ & $423(42.1)$ & \\
\hline$\$ 15,000-\$ 29,999$ & $1159(42.0)$ & $757(43.1)$ & $402(40.0)$ & \\
\hline$\geq \$ 30,000$ & $910(33.0)$ & $731(41.6)$ & $179(17.8)$ & \\
\hline Marital status & & & & 0.107 \\
\hline Unmarried & $161(5.8)$ & $112(6.4)$ & $49(4.9)$ & \\
\hline Married & $2600(94.2)$ & 1645 (93.6) & 955(95.1) & \\
\hline Work full-time during pregnancy & & & & $<0.001$ \\
\hline No & $795(28.8)$ & $331(18.8)$ & $464(46.2)$ & \\
\hline Yes & $1966(71.2)$ & $1426(81.2)$ & $540(53.8)$ & \\
\hline Work full-time post-partum & & & & $<0.001$ \\
\hline No & $1167(42.3)$ & $543(30.9)$ & $624(62.2)$ & \\
\hline Yes & $1594(57.7)$ & $1214(69.1)$ & $380(37.9)$ & \\
\hline Maternal smoking & & & & $<0.001$ \\
\hline No & $2667(96.6)$ & 1679 (95.6) & $988(98.4)$ & \\
\hline Yes & $94(3.4)$ & $78(4.4)$ & $16(1.6)$ & \\
\hline Paternal smoking & & & & 0.085 \\
\hline No & $1852(67.1)$ & 1199 (68.2) & $653(65.0)$ & \\
\hline Yes & 909 (32.9) & $558(31.8)$ & $351(35.0)$ & \\
\hline Pre-pregnancy health problem & & & & 0.979 \\
\hline No & $2525(91.5)$ & $1607(91.5)$ & $918(91.4)$ & \\
\hline Yes & $236(8.6)$ & $150(8.5)$ & $86(8.6)$ & \\
\hline Pregnancy-related health problem & & & & 0.817 \\
\hline No & $2387(86.5)$ & $1521(86.6)$ & $866(86.3)$ & \\
\hline Yes & $374(13.6)$ & $236(13.4)$ & $138(13.8)$ & \\
\hline
\end{tabular}


Table 1 Characteristics of the sample (Continued)

\begin{tabular}{llll}
\hline Delivery type & & & 0.122 \\
Spontaneous vaginal & $1902(68.9)$ & $1187(67.6)$ & $715(71.2)$ \\
Assisted vaginal & $139(5.0)$ & $96(5.5)$ & $43(4.3)$ \\
Planned cesarean & $365(13.2)$ & $233(13.3)$ & $132(13.2)$ \\
Emergency cesarean & $355(12.9)$ & $241(13.7)$ & $114(11.4)$ \\
Preterm birth & & & $925(92.1)$ \\
No & $2546(92.2)$ & $1621(92.3)$ & $79(7.9)$ \\
Yes & $215(7.8)$ & $136(7.7)$ & \\
Infant LBWc & & $1599(91.0)$ & $941(93.7)$ \\
No & $2540(92.0)$ & $158(9.0)$ & $63(6.3)$ \\
Yes & $221(8.0)$ & & 0.011 \\
\hline
\end{tabular}

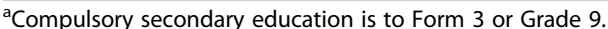

${ }^{\mathrm{b}} 1 \mathrm{USD}=7.78 \mathrm{HKD}$

${ }^{c} L B W$ Low birth weight

full-term (92.2\%) and normal birth weight infants (92\%). When compared with Mainland China born women, participants born in Hong Kong were more likely to be primiparas (59.4 vs. $42.5 \%$ ), to have a university degree (27.6 vs. $12.8 \%$ ) and higher household income (41.6 vs. $17.8 \%$ ), and to work full-time during pregnancy ( 81.2 vs. $53.8 \%$ ) and after giving birth (69.1 vs. $37.9 \%)$.

Several characteristics were significantly associated with breastfeeding initiation in Hong Kong born and Mainland China born mothers (Table 2). In both groups, breastfeeding initiators were significantly more likely to be primiparas, have a university degree, work full-time during pregnancy and be non-smokers with non-smoking partners. In Hong Kong born participants, breastfeeding initiators were more likely to be older, married with a higher household income, and returning to work full-time postpartum. Hong Kong born participants who had a planned cesarean section were less likely to initiate breastfeeding and there was some evidence of lower breastfeeding in low birth weight infants, but the relationship was not statistically significant. In Mainland China born participants, breastfeeding initiation was not significantly associated with maternal age, household income, delivery status and returning to work postpartum but participants with pregnancy-related health problems were less likely to initiate breastfeeding. In both groups, breastfeeding initiation was not significantly associated with pre-pregnancy health problems or pre-term birth.

Table 3 presents the stratified and combined results of multivariable logistic regression analyses of predictors of breastfeeding initiation. In both the stratified and combined analyses, multiparity (OR $0.53,95 \%$ CI $0.43-0.66$ ) and maternal smoking (OR 0.29, $95 \%$ CI 0.18-0.45) were significantly associated with lower rates of breastfeeding initiation. In Hong Kong born participants, lower education levels and cesarean birth were associated with lower breastfeeding initiation. In Mainland China born participants, paternal smoking and having a pregnancy-related disease were also associated with lower rates of breastfeeding initiation. Family income was not clearly associated with breastfeeding initiation in either group of participants. Although in the stratified analysis, participants returning to work postpartum were less likely to initiate breastfeeding, the results were not statistically significant. In the combined analysis, however, participants who returned to work full-time were significantly less likely to initiate breastfeeding (OR 0.72, 95 \% CI 0.54-0.95). Although preterm infants were not less likely to be breastfed, there is some indication that participants with low birth weight (LBW) infants were less like to initiate breastfeeding (OR 0.66, $95 \%$ CI 0.43-1.02). However, the association did not reach the level of statistical significance. The results of the Hosmer-Lemeshow goodness-of-fit tests for the logistic regression models $(P>.10)$ indicated that the models were a good fit for the data.

\section{Discussion}

In this study we examined breastfeeding initiation patterns among postpartum women born in Hong Kong and Mainland China and identified some common and disparate predictors of breastfeeding initiation. Overall, there was a high breastfeeding initiation rate among all participants, with equal rates in both groups. Multiparity and maternal and paternal smoking were risk factors for lower breastfeeding initiation in both groups. In Hong Kong mothers, as has been found in other studies [32, 33, 40, 41], breastfeeding initiation is strongly associated with higher maternal education. Hong Kong born participants with the lowest education level were $70 \%$ less likely to initiate breastfeeding than participants in the highest education category. However, in contrast to studies in other countries [32,33], higher family income was not significantly associated with breastfeeding 
Table $\mathbf{2}$ Characteristics of breastfeeding initiators versus non-initiators by birthplace

\begin{tabular}{|c|c|c|c|c|c|c|c|c|c|}
\hline \multirow[t]{4}{*}{ Characteristic } & \multicolumn{2}{|l|}{ Hong Kong } & \multirow{4}{*}{$P$-value } & \multicolumn{2}{|c|}{ Mainland China } & \multirow{4}{*}{$P$-value } & \multicolumn{2}{|l|}{ All } & \multirow{4}{*}{$P$-value } \\
\hline & No & Yes & & No & Yes & & No & Yes & \\
\hline & $(N=346)$ & $(N=1411)$ & & $(N=190)$ & $(N=814)$ & & $(N=536)$ & $(N=2225)$ & \\
\hline & N (\%) & N (\%) & & N (\%) & N (\%) & & N (\%) & N (\%) & \\
\hline Maternal age (years) & & & .022 & & & .158 & & & .009 \\
\hline $18-24$ & $39(24.5)$ & $120(75.5)$ & & $23(21.7)$ & $83(78.3)$ & & $62(23.4)$ & 203 (76.6) & \\
\hline $25-29$ & $97(23.2)$ & $322(76.9)$ & & $55(18.8)$ & $238(81.2)$ & & $152(21.4)$ & $560(78.7)$ & \\
\hline $30-34$ & $116(16.6)$ & $581(83.4)$ & & $51(15.4)$ & $280(84.6)$ & & $167(16.3)$ & $861(83.8)$ & \\
\hline$\geq 35$ & 94 (19.5) & 388 (80.5) & & $61(22.3)$ & $213(77.7)$ & & 155 (20.5) & $601(79.5)$ & \\
\hline Parity & & & $<.001$ & & & .002 & & & $<.001$ \\
\hline Primiparous & $156(15.0)$ & $887(85.0)$ & & $62(14.5)$ & 365 (85.5) & & $218(14.8)$ & $1252(85.2)$ & \\
\hline Multiparous & $190(26.6)$ & $524(73.4)$ & & $128(22.2)$ & $449(77.8)$ & & $328(24.6)$ & $973(75.4)$ & \\
\hline Maternal education & & & $<.001$ & & & .039 & & & $<.001$ \\
\hline Compulsory secondary or below ${ }^{a}$ & $257(27.1)$ & $692(72.9)$ & & $148(20.8)$ & $565(79.2)$ & & $405(24.4)$ & $1275(75.6)$ & \\
\hline Upper secondary & $54(16.7)$ & $269(83.3)$ & & 27 (16.6) & $136(83.4)$ & & $81(16.7)$ & $405(83.3)$ & \\
\hline University degree or above & $35(7.2)$ & $450(92.8)$ & & $15(11.7)$ & $113(88.3)$ & & $50(8.2)$ & $563(91.8)$ & \\
\hline Monthly family income (HKD) & & & $<.001$ & & & .063 & & & $<.001$ \\
\hline$<\$ 15,000$ & $87(32.3)$ & $182(67.7)$ & & $94(22.2)$ & $329(77.8)$ & & $181(26.2)$ & $511(73.8)$ & \\
\hline$\$ 15,000-\$ 29,999$ & $169(22.3)$ & $588(77.7)$ & & $69(17.2)$ & $333(82.8)$ & & $238(20.5)$ & $921(79.5)$ & \\
\hline$\geq \$ 30,000$ & $90(12.3)$ & $641(87.7)$ & & $27(15.1)$ & $152(84.9)$ & & $117(12.9)$ & $793(87.1)$ & \\
\hline Length of time in Hong Kong & & & & & & .219 & & & \\
\hline$<5$ years & - & - & & 45 (17.6) & $211(82.4)$ & & - & - & \\
\hline $5-<10$ years & - & - & & $39(16.2)$ & $202(83.8)$ & & - & - & \\
\hline$\geq 10$ years & - & - & & $104(21.1)$ & $388(78.9)$ & & - & - & \\
\hline Marital status & & & $<.001$ & & & .077 & & & $<.001$ \\
\hline Unmarried & $39(34.8)$ & $73(65.2)$ & & $14(28.6)$ & $35(71.4)$ & & $53(32.9)$ & $108(67.1)$ & \\
\hline Married & $307(18.7)$ & $1338(81.3)$ & & $176(18.4)$ & 779 (81.6) & & $483(18.6)$ & $2117(81.4)$ & \\
\hline Work full-time during pregnancy & & & $<.001$ & & & .009 & & & $<.001$ \\
\hline No & $97(29.3)$ & $234(70.7)$ & & $104(22.4)$ & $360(77.6)$ & & $201(25.3)$ & $594(74.7)$ & \\
\hline Yes & $249(17.5)$ & $1177(82.5)$ & & $86(15.9)$ & $454(84.1)$ & & $335(17.0)$ & $1631(83.0)$ & \\
\hline Work full-time post-partum & & & $<.001$ & & & .139 & & & .001 \\
\hline No & $134(24.7)$ & $409(75.3)$ & & $127(20.4)$ & $497(79.7)$ & & $261(22.4)$ & 906 (77.6) & \\
\hline Yes & $212(17.5)$ & $1002(82.5)$ & & $63(16.6)$ & $317(83.4)$ & & $275(17.3)$ & 1319 (82.8) & \\
\hline Maternal smoking & & & $<.001$ & & & $<.001$ & & & $<.001$ \\
\hline No & $307(18.3)$ & $1372(81.7)$ & & $179(18.1)$ & $809(81.9)$ & & $486(18.2)$ & $2181(81.8)$ & \\
\hline Yes & $39(50.0)$ & $39(50.0)$ & & $11(68.8)$ & $5(31.3)$ & & $50(53.2)$ & $44(46.8)$ & \\
\hline Paternal smoking & & & $<.001$ & & & .001 & & & $<.001$ \\
\hline No & $191(15.9)$ & $1008(84.1)$ & & $103(15.8)$ & $550(84.2)$ & & $294(15.9)$ & $1558(84.1)$ & \\
\hline Yes & $155(27.8)$ & $403(72.2)$ & & $87(24.8)$ & $264(75.2)$ & & $242(26.6)$ & $667(73.4)$ & \\
\hline Pre-pregnancy health problem & & & .330 & & & .053 & & & .707 \\
\hline No & $321(20.0)$ & $1286(80.0)$ & & $167(18.2)$ & $751(81.8)$ & & $488(19.3)$ & $2037(80.7)$ & \\
\hline Yes & $25(16.7)$ & $125(83.3)$ & & $23(26.7)$ & $63(73.3)$ & & $48(20.3)$ & $188(79.7)$ & \\
\hline
\end{tabular}


Table 2 Characteristics of breastfeeding initiators versus non-initiators by birthplace (Continued)

\begin{tabular}{|c|c|c|c|c|c|c|c|c|c|}
\hline Pregnancy-related health problem & & & .251 & & & .011 & & & .014 \\
\hline No & $293(19.3)$ & $1228(80.7)$ & & $153(17.7)$ & $713(82.3)$ & & $446(18.7)$ & $1941(81.3)$ & \\
\hline Yes & $53(22.5)$ & $183(77.5)$ & & $37(26.8)$ & $101(73.2)$ & & $90(24.1)$ & $284(75.9)$ & \\
\hline Delivery type & & & .044 & & & .384 & & & .095 \\
\hline Spontaneous vaginal & $214(18.0)$ & $973(82.0)$ & & $139(19.4)$ & $576(80.6)$ & & $353(18.6)$ & $1549(81.4)$ & \\
\hline Assisted vaginal & $21(21.9)$ & $75(78.1)$ & & $8(18.6)$ & $35(81.4)$ & & $29(20.9)$ & $110(79.1)$ & \\
\hline Planned cesarean & $60(25.8)$ & $173(74.3)$ & & $28(21.2)$ & $104(78.8)$ & & $88(24.1)$ & $277(75.9)$ & \\
\hline Emergency cesarean & $51(21.2)$ & $190(78.8)$ & & $15(13.2)$ & $99(86.8)$ & & $66(18.6)$ & $289(81.4)$ & \\
\hline Preterm birth & & & .105 & & & .753 & & & .138 \\
\hline No & $312(19.3)$ & $1309(80.8)$ & & $174(18.8)$ & $751(81.2)$ & & $486(19.1)$ & $2060(80.9)$ & \\
\hline Yes & $34(25.0)$ & $102(75.0)$ & & $16(20.3)$ & $63(79.8)$ & & $50(23.3)$ & $165(76.7)$ & \\
\hline Infant LBW ${ }^{c}$ & & & .062 & & & .720 & & & .073 \\
\hline No & 306 (19.1) & 1293 (80.9) & & 177 (18.8) & $764(81.2)$ & & $483(19.0)$ & $2057(81.0)$ & \\
\hline Yes & $40(25.3)$ & $118(74.7)$ & & 13 (20.6) & $50(79.4)$ & & $53(24.0)$ & $168(76.0)$ & \\
\hline
\end{tabular}

${ }^{a}$ Compulsory secondary education is to Form 3 or Grade 9

$\mathrm{b}_{1} \mathrm{USD}=7.78 \mathrm{HKD}$

' $L B W$ Low birth weight

initiation in either group. In Mainland Chinese women, breastfeeding initiation is less socially patterned with no significant associations between sociodemographic and socioeconomic indicators and initiation rates.

The breastfeeding initiation rate reported in this study is high and generally consistent with that reported by other parties. The annual Hong Kong breastfeeding survey reported that in 2010, $79.2 \%$ of all mothers left the hospital breastfeeding [42]. However, the survey did find that in public hospitals, the same sample as our study, the breastfeeding initiation rate was only $71.3 \%$. Although breastfeeding initiation rates in Hong Kong are high relative to some other countries $[43,44]$, there is further room for improvement as many developed countries such as Australia, Canada, Denmark, Norway and Sweden all have breastfeeding initiation rates in excess of $90 \%[3,45,46]$. If breastfeeding initiation rates are to be improved beyond the current rate, targeted strategies are required. Thus, information gained from this study can be used to identify new mothers who are at risk for not initiating breastfeeding and provide them with additional evidence-based and cost-effective antenatal breastfeeding support. Furthermore, despite these high initiation rates, breastfeeding duration in Hong Kong remains short, with about onehalf of all mothers who initiate breastfeeding stopping within the first three months [47]. Early breastfeeding cessation in Hong Kong has been attributed to sociocultural variables such as lack of family and community support for breastfeeding [26, 48-51], hospital practices that don't adequately support breastfeeding [52-54], high workforce participation rates among childbearing women [29], and poor workplace accommodations for breastfeeding mothers [55]. Therefore, focus is also needed on how to sustain breastfeeding once it has been started and how best to provide support for breastfeeding mothers.

Consistent with previous studies [20-22, 40, 56], multiparity was negatively associated with breastfeeding initiation among all participants in this study. Why multiparous mothers are less likely to breastfeed is not clear. Multiparous mothers face greater time constraints in caring for multiple children and a second born child may be less likely to cause the same maternal anxiety and sense of novelty as compared with a firstborn [57]. In addition, when compared with primiparas, multiparous mothers may perceive less necessity to prove their maternal skills [58]. Other researchers have reported that mothers have more interaction with a first-born child than they have with subsequent children $[57,59]$. These factors may contribute to lower breastfeeding initiation rates among multiparous mothers.

As has been found in other studies [21, 32, 40], we found that both maternal and paternal smoking were significantly associated with lower odds of breastfeeding. Although the overall rate of smoking in our population was low (3.3\%), especially when compared with rates reported in other studies $[32,40,60]$, the impact was still substantial. When compared with non-smokers, participants who smoked were 60-80 \% less likely to initiate breastfeeding. In addition, participants whose partners' smoked were 20-30\% less likely to initiate breastfeeding. Because of public health messages encouraging smoking cessation during pregnancy and breastfeeding, new mothers who continue to smoke may believe that formula milk is healthier for their infant than breast milk from a smoking mother [40]. Other researchers have hypothesized that the relationship between maternal smoking and breastfeeding is confounded by socioeconomic status [21], whereby low rates of 
Table 3 Adjusted odds ratios (aOR) for breastfeeding initiation by birth place and for the total sample

\begin{tabular}{|c|c|c|c|c|c|c|}
\hline \multirow[b]{2}{*}{ Characteristic } & \multicolumn{2}{|c|}{ Hong Kong born } & \multicolumn{2}{|c|}{ Mainland China born } & \multicolumn{2}{|c|}{ All participants } \\
\hline & $\mathrm{aOR}^{\mathrm{a}}$ & $(95 \% \mathrm{Cl})$ & $\mathrm{aOR}^{\mathrm{a}}$ & $(95 \% \mathrm{Cl})$ & $\mathrm{aOR}^{\mathrm{a}}$ & $(95 \% \mathrm{Cl})$ \\
\hline \multicolumn{7}{|l|}{ Maternal age (years) } \\
\hline $18-24$ & 1 & - & 1 & - & 1 & - \\
\hline $25-29$ & 0.71 & $(0.44,1.16)$ & 1.11 & $(0.61,2.00)$ & 0.86 & $(0.59,1.25)$ \\
\hline $30-34$ & 0.97 & $(0.59,1.58)$ & 1.47 & $(0.80,2.71)$ & 1.12 & $(0.77,1.63)$ \\
\hline$\geq 35$ & 0.90 & $(0.54,1.51)$ & 1.02 & $(0.55,1.87)$ & 0.97 & $(0.65,1.43)$ \\
\hline \multicolumn{7}{|l|}{ Parity } \\
\hline Primiparous & 1 & - & 1 & - & 1 & - \\
\hline Multiparous & 0.46 & $(0.35,0.61)$ & 0.59 & $(0.40,0.86)$ & 0.53 & $(0.43,0.66)$ \\
\hline \multicolumn{7}{|l|}{ Maternal education } \\
\hline Compulsory secondary or below ${ }^{b}$ & 0.29 & $(0.19,0.45)$ & 0.67 & $(0.35,1.31)$ & 0.36 & $(0.25,0.52)$ \\
\hline Upper secondary & 0.42 & $(0.26,0.67)$ & 0.73 & $(0.36,1.51)$ & 0.49 & $(0.33,0.72)$ \\
\hline University degree or above & 1 & & 1 & & 1 & \\
\hline \multicolumn{7}{|l|}{ Monthly family income $(H K D)^{c}$} \\
\hline$<\$ 15,000$ & 1 & - & 1 & - & 1 & - \\
\hline$\$ 15,000-\$ 29,999$ & 1.10 & $(0.76,1.58)$ & 1.20 & $(0.82,1.76)$ & 1.06 & $(0.82,1.36)$ \\
\hline$\geq \$ 30,000$ & 1.42 & $(0.91,2.23)$ & 1.09 & $(0.61,1.96)$ & 1.20 & $(0.85,1.68)$ \\
\hline \multicolumn{7}{|l|}{ Marital status } \\
\hline Unmarried & 1 & - & 1 & - & 1 & - \\
\hline Married & 1.24 & $(0.77,2.00)$ & 1.89 & $(0.93,3.82)$ & 1.46 & $(0.99,2.14)$ \\
\hline \multicolumn{7}{|l|}{ Work full-time during pregnancy } \\
\hline No & 1 & - & 1 & - & 1 & - \\
\hline Yes & 1.42 & $(0.95,2.12)$ & 1.30 & $(0.83,2.04)$ & 1.29 & $(0.96,1.74)$ \\
\hline \multicolumn{7}{|l|}{ Work full-time post-partum } \\
\hline No & 1 & - & 1 & - & 1 & - \\
\hline Yes & 0.74 & $(0.51,1.06)$ & 0.79 & $(0.49,1.27)$ & 0.72 & $(0.54,0.95)$ \\
\hline \multicolumn{7}{|l|}{ Maternal smoking } \\
\hline No & 1 & - & 1 & - & 1 & - \\
\hline Yes & 0.36 & $(0.21,0.61)$ & 0.13 & $(0.04,0.41)$ & 0.29 & $(0.18,0.45)$ \\
\hline \multicolumn{7}{|l|}{ Paternal smoking } \\
\hline No & 1 & - & 1 & - & 1 & - \\
\hline Yes & 0.80 & $(0.60,1.05)$ & 0.70 & $(0.49,0.99)$ & 0.75 & $(0.60,0.92)$ \\
\hline \multicolumn{7}{|l|}{ Pre-pregnancy health problem } \\
\hline No & 1 & - & 1 & - & 1 & - \\
\hline Yes & 1.22 & $(0.76,1.98)$ & 0.65 & $(0.38,1.10)$ & 0.94 & $(0.66,1.34)$ \\
\hline \multicolumn{7}{|l|}{ Pregnancy-related problem } \\
\hline No & 1 & - & 1 & - & 1 & - \\
\hline Yes & 0.85 & $(0.59,1.21)$ & 0.60 & $(0.38,0.94)$ & 0.73 & $(0.55,0.96)$ \\
\hline \multicolumn{7}{|l|}{ Delivery type } \\
\hline Spontaneous vaginal & 1 & - & 1 & - & 1 & - \\
\hline Assisted vaginal & 0.60 & $(0.35,1.03)$ & 0.84 & $(0.37,1.93)$ & 0.65 & $(0.42,1.03)$ \\
\hline Planned cesarean & 0.63 & $(0.44,0.90)$ & 0.94 & $(0.58,1.53)$ & 0.73 & $(0.55,0.97)$ \\
\hline Emergency cesarean & 0.63 & $(0.43,0.92)$ & 1.52 & $(0.82,2.82)$ & 0.83 & $(0.61,1.13)$ \\
\hline
\end{tabular}


Table 3 Adjusted odds ratios (aOR) for breastfeeding initiation by birth place and for the total sample (Continued)

\begin{tabular}{|c|c|c|c|c|c|c|}
\hline \multicolumn{7}{|c|}{ Preterm birth } \\
\hline No & 1 & - & 1 & - & 1 & - \\
\hline Yes & 0.96 & $(0.54,1.70)$ & 0.97 & $(0.47,2.00)$ & 1.00 & $(0.65,1.55)$ \\
\hline \multicolumn{7}{|c|}{ Infant LBW' } \\
\hline No & 1 & - & 1 & - & 1 & - \\
\hline Yes & 0.64 & $(0.38,1.09)$ & 0.71 & $(0.32,1.56)$ & 0.66 & $(0.43,1.02)$ \\
\hline
\end{tabular}

adjusted for variables shown

${ }^{b}$ Compulsory secondary education is to Form 3 or Grade 9

${ }^{c} 1$ USD $=7.78$ HKD

d $L B W$ Low birth weight

breastfeeding and high rates of smoking are more common in lower socioeconomic status individuals. Although we controlled for various socioeconomic indicators in our analysis and the relationship between smoking and breastfeeding initiation was still observed, we cannot rule out the possibility of residual confounding as smoking patterns are increasingly socioeconomically determined in most populations [61]. Given the consequences of maternal smoking on the fetus and on infants [62-64], pregnant women should be strongly encouraged to quit smoking. However, the benefits of breastfeeding outweigh the negative effects of exposure to nicotine through the breast milk and breastfeeding should still be promoted even in the absence of smoking cessation [65].

Birth by cesarean section was also a major barrier to breastfeeding initiation in Hong Kong born mothers. Although some studies have found no relationship between mode of delivery and breastfeeding initiation [66, 67], many have found that operative birth is a significant barrier to breastfeeding initiation [32, 68-71]. Previous studies, however, have rarely distinguished between the reasons for cesarean section (i.e., planned or emergency) and the impact on breastfeeding initiation. Overall, cesarean section rates were moderate in this study (26\%), especially in comparison to those reported in other countries [72-74], and are consistent with Hong Kong public hospital cesarean section rates reported elsewhere [75]. Furthermore, participants in this study undergoing a planned or scheduled cesarean section were doing so because it was medically indicated. Public hospitals in Hong Kong do not permit cesarean section upon maternal request, so all scheduled operative deliveries were deemed medically necessary. Thus, women who know that they will have a scheduled cesarean section may decide not to breastfeed because of anticipation of postoperative pain and discomfort. In addition, cesarean births and analgesia often increase maternal discomfort postpartum, cause separation of the mother and infant after birth, disrupt an infant's natural breastfeeding reflexes, and thus increase problems with breastfeeding initiation $[76,77]$. To allow mothers with cesarean sections adequate time to rest after surgery, infants are often given formula supplements before breastfeeding is initiated [53], further disrupting the initiation of breastfeeding. Therefore, antenatal breastfeeding education should target mothers known to be having a cesarean section and adequate postpartum support should be provided to all mothers who have a cesarean section to enable them to initiate breastfeeding as early as possible after birth.

Although preterm birth was not associated with breastfeeding, there was a strong, albeit statistically insignificant, association between LBW and breastfeeding initiation in the total sample. Because of the small number of infants born with LBW $(n=221)$ there was insufficient power to adequately assess this association. However, previous research in Hong Kong also found that LBW was a risk factor for failure to breastfeed [25] and studies in other countries have reported similar findings [78-80]. Although studies have repeatedly shown that human milk feeding of premature and LBW infants produces better health and developmental outcomes than infant formula [81-83], unfortunately many of these at risk newborns were never breastfed.

\section{Strengths and limitations}

This study is one of the first to investigate the patterns and predictors of breastfeeding initiation in Hong Kong and Mainland China born mothers. The sample was large and population-based and captured a substantial proportion of eligible new mothers. Breastfeeding initiation status was extracted from the ward record book and then verified with the participants, thus increasing the accuracy of the outcome variable. Conversely, many of our other variables of interest relied on maternal selfreport and response bias cannot be ruled out. However, given that the main focus of our original study was not breastfeeding [35], the possibility of social desirability bias was minimized. Furthermore, reported maternal smoking rates $(3.3 \%)$, an indicator that would be highly susceptible to social desirability bias, mirror the rates of female smoking $(3.1 \%)$ reported in population based surveys [84]. In addition, it is possible that breastfeeding decisions were influenced by variables that were not measured in our study such as the melamine tainted infant formula scandal in Mainland China [85]. Many 
experts agree, however, that the impact of this scandal on breastfeeding in Hong Kong and China was minimal [86] and it primarily served to create a large market for foreign infant formula brands in China [87, 88]. Finally, we do not have any information on mothers who refused to take part in this study and thus we do not know if they are similar or different from participants in ways that may affect the study findings.

\section{Conclusions}

Results from this study show that breastfeeding initiation rates are high in Hong Kong born and Mainland China born mothers, with no significant differences between the two groups. However, there is potential to further increase breastfeeding initiation rates and data from this study has identified a number of predictors unique to each group that can help clinicians and public health professionals to further promote breastfeeding in Hong Kong. Given the current high breastfeeding initiation rates, evidence-based antenatal breastfeeding education and promotion programmes can be directed at sub-groups of pregnant women with lower initiation rates so that their efforts are more strategic and cost-effective.

\section{Competing interests}

The authors declare that they have no competing interests.

\section{Authors' contributions}

$\mathrm{KL}$ performed data analysis and wrote the first draft of the paper. DB assisted with data analysis and critically reviewed and revised the final draft of the paper. MT designed the study, obtained funding, oversaw the implementation of the study, and critically reviewed and revised the final draft of the manuscript. The manuscript has been read and approved for publication by all authors.

\section{Acknowledgements \\ Funding for this study was provided by the Health and Medical Research Fund, Government of the Hong Kong Special Administrative Region, Hong Kong SAR (Grant No. 10090982). The funding body had no role in the study design, the collection, analysis, and interpretation of data, the writing of the manuscript, or the decision to submit the manuscript for publication. The authors want to thank Hawthorn Cheung, Katherine Lam, Ebby Hui, Brenda Law, Connie Chiu, Stephanie Lam, Ryanne Kun, and Diana Tin for their assistance with participant recruitment and data collection. Special thanks to Vincci Chan for assistance with the study management and coordination.}

Received: 15 April 2015 Accepted: 23 October 2015

Published online: 03 November 2015

\section{References}

1. World Health Organization. Global strategy for infant and young child feeding. In: vol. A54/INF.DOC/4. Geneva: World Health Organization; 2003.

2. American Academy of Pediatrics. Policy statement: breastfeeding and the use of human milk. Pediatrics. 2012;129(3):e827-41.

3. Breastfeeding rate [Internet]. Paris: Organisation for Economic Co-operation and Development. OECD; 2009 Oct 1 [Cited 2015 Oct 28]; Available from: [http://www.oecd.org/social/family/43136964.pdf]. Access date: 2015 Oct 28.

4. Besculides M, Grigoryan K, Laraque F. Increasing breastfeeding rates in New York City, 1980-2000. J Urban Health. 2005;82(2):198-206.

5. Callen J, Pinelli J. Incidence and duration of breastfeeding for term infants in Canada, United States, Europe, and Australia: a literature review. Birth. 2004;31(4):285-92.
6. Foo LL, Quek SJS, Ng SA, Lim MT, Deurenberg-Yap M. Breastfeeding prevalence and practices among Singaporean Chinese, Malay and Indian mothers. Health Promot Int. 2005;20(3):229-37.

7. Li R, Zhao Z, Mokdad A, Barker L, Grummer-Strawn L. Prevalence of breastfeeding in the United States: the 2001 National Immunization Survey. Pediatrics. 2003;111(5 Part 2):1198-201.

8. Riva E, Banderali G, Agostoni C, Silano M, Radaelli G, Giovannini M. Factors associated with initiation and duration of breastfeeding in Italy. Acta Paediatr. 1999;88(4):411-5.

9. Clements MS, Mitchell EA, Wright SP, Esmail A, Jones DR, Ford RPK. Influences on breastfeeding in southeast England. Acta Paediatr. 1997;86(1):51-6.

10. Scott JA, Aitkin I, Binns CW, Aroni RA. Factors associated with the duration of breastfeeding amongst women in Perth, Australia. Acta Paediatr. 1999;88(4):416-21.

11. Leung GM, Lam TH, Ho LM, Lau YL. Health consequences of breastfeeding: doctors' visits and hospitalisations during the first 18 months of life in Hong Kong Chinese infants. Epidemiology. 2005;16(3):328-35.

12. Tarrant M, Kwok MK, Lam TH, Leung GM, Schooling CM. Breast-feeding and childhood hospitalizations for infections. Epidemiology. 2010;21(6):847-54.

13. Oddy WH, Kickett-Tucker C, De Maio J, Lawrence D, Cox A, Silburn SR, et al. The association of infant feeding with parent-reported infections and hospitalisations in the West Australian Aboriginal Child Health Survey. Aust N Z J Public Health. 2008;32(3):207-15.

14. Paricio Talayero JM, Lizan-Garcia M, Otero Puime A, Benlloch Muncharaz MJ, Beseler Soto B, Sanchez-Palomares M, et al. Full breastfeeding and hospitalization as a result of infections in the first year of life. Pediatrics. 2006;118(1):e92-9.

15. Kramer MS, Guo T, Platt RW, Vanilovich I, Sevkovskaya Z, Dzikovich I, et al. Feeding effects on growth during infancy. J Pediatr. 2004;145(5):600-5.

16. Feng $L P, C$ Chen $H L$, Shen MY. Breastfeeding and the risk of ovarian cancer: a meta-analysis. J Midwifery Womens Health. 2014;59(4):428-37.

17. Newcomb PA, Storer BE, Longnecker MP, Mittendorf R, Greenberg ER, Clapp RW, et al. Lactation and a reduced risk of premenopausal breast cancer. NEJM. 1994;330(2):81-7.

18. Khin PP, Cheung SL, Loh T. Support and promotion of breastfeeding. Where are we now? Public Health Epidemiol Bull. 2002;11(3):25-32.

19. Baby Friendly Hospital Initiative Hong Kong Association. World breastfeeding week 2013: annual summary. Hong Kong: Author; 2013.

20. McInnes RJ, Love JG, Stone DH. Independent predictors of breastfeeding intention in a disadvantaged population of pregnant women. BMC Public Health. 2001;1:10.

21. Leung GM, Ho LM, Lam TH. Maternal, paternal and environmental tobacco smoking and breast feeding. Paediatr Perinat Epidemiol. 2002;16(3):236-45.

22. Yang Q, Wen SW, Dubois L, Chen Y, Walker MC, Krewski D. Determinants of breast-feeding and weaning in Alberta, Canada. JOGC. 2004;26(11):975-81.

23. Noble L, Hand I, Haynes D, McVeigh T, Kim M, Yoon JJ. Factors influencing initiation of breast-feeding among urban women. Am J Perinatol. 2003;20(8):477-83.

24. Kogan MD, Singh GK, Dee DL, Belanoff C, Grummer-Strawn LM. Multivariate analysis of state variation in breastfeeding rates in the United States. Am J Public Health. 2008:98(10):1872-80.

25. Leung GM, Ho LM, Lam TH. Breastfeeding rates in Hong Kong: a comparison of the 1987 and 1997 birth cohorts. Birth. 2002;29(3):162-8.

26. Tarrant M, Fong DY, Wu KM, Lee IL, Wong EM, Sham A, et al. Breastfeeding and weaning practices among Hong Kong mothers: a prospective study. BMC Pregnancy Childbirth. 2010;10:27.

27. Kwok MK, Schooling CM, Lam TH, Leung GM. Does breastfeeding protect against childhood overweight? Hong Kong's 'Children of 1997' birth cohort. Int J Epidemiol. 2010;39:297-305.

28. Kennedy KJ. Immigration and Hong Kong: "New immigrants" and ethnic minorities. In: UNESCO-KEDI Regional Policy Seminar 2012 - Education policy: Making in the age of migration in Asia and the Pacific. Bangkok: UNESCO-KEDI; 2012.

29. 2011 Population census: summary results [Internet]. Hong Kong: Census and Statistics Department; 2012 Feb [cited 2015 Oct 28]. Available from: http:// www.census2011.gov.hk/pdf/summary-results.pdf.

30. Xu F, Qiu L, Binns CW, Liu X. Breastfeeding in China: a review. Int Breastfeed J. 2009;4:6.

31. Chen S, Binns CW, Zhao Y, Maycock B, Liu Y. Breastfeeding by Chinese mothers in Australia and China: the healthy migrant effect. J Hum Lact. 2013;29(2):246-52. 
32. Chin AC, Myers L, Magnus JH. Race, education, and breastfeeding initiation in Louisiana, 2000-2004. J Hum Lact. 2008;24(2):175-85.

33. Celi AC, Rich-Edwards JW, Richardson MK, Kleinman KP, Gillman MW. Immigration, race/ethnicity, and social and economic factors as predictors of breastfeeding initiation. Arch Pediatr Adolesc Med. 2005;159(3):255-60.

34. Li R, Ogden C, Ballew C, Gillespie C, Grummer-Strawn L. Prevalence of exclusive breastfeeding among US infants: the Third National Health and Nutrition Examination Survey (Phase II, 1991-1994). Am J Public Health. 2002;92(7):1107-10.

35. Yuen CYS, Fong DYT, Lee ILY, Sing C, Siu ES-m, Tarrant M. Prevalence and predictors of maternal seasonal influenza vaccination in Hong Kong. Vaccine. 2013;31(45):5281-8.

36. Latest arrangement for non-local pregnant women giving birth in Hong Kong [Internet]. Hong Kong: Food and Health Bureau; 2012 May 7 [cited 2015 Oct 28]. Available from: http://www.legco.gov.hk/yr11-12/english/ panels/hs/papers/hs0507cb2-1863-1-e.pdf

37. von Elm E, Altman DG, Egger M, Pocock SJ, Gotzsche PC, Vandenbroucke JP, et al. The Strengthening the Reporting of Observational Studies in Epidemiology (STROBE) statement: guidelines for reporting observational studies. Epidemiology. 2007;18(6):800-4.

38. Hosmer DW, Hosmer T, Le Cessie S, Lemeshow S. A comparison of goodnessof-fit tests for the logistic regression model. Stat Med. 1997;16(9):965-80.

39. StataCorp. Stata statistical software: release 13.1. College Station: StataCorp LP; 2013.

40. Bailey BA, Wright HN. Breastfeeding initiation in a rural sample: predictive factors and the role of smoking. J Hum Lact. 2011;27(1):33-40.

41. Baxter J, Cooklin AR, Smith J. Which mothers wean their babies prematurely from full breastfeeding? An Australian cohort study. Acta Paediatr. 2009;98(8):1274-7.

42. Baby Friendly Hospital Initiative Hong Kong Association. World breastfeeding week 2010: annual summary. Hong Kong: Author; 2011.

43. Tarrant RC, Younger KM, Sheridan-Pereira M, White MJ, Kearney JM. The prevalence and determinants of breast-feeding initiation and duration in a sample of women in Ireland. Public Health Nutr. 2010;13(6):760-70.

44. Cattaneo A, Burmaz T, Arendt M, Nilsson I, Mikiel-Kostyra K, Kondrate I, et al. Protection, promotion and support of breast-feeding in Europe: progress from 2002 to 2007. Public Health Nutr. 2010;13(6):751-9.

45. Watt S, Sword W, Sheehan D, Foster G, Thabane L, Krueger P, et al. The effect of delivery method on breastfeeding initiation from the The Ontario Mother and Infant Study (TOMIS) III. JOGNN. 2012;41(6):728-37.

46. Hauck YL, Fenwick J, Dhaliwal SS, Butt J. A Western Australian survey of breastfeeding initiation, prevalence and early cessation patterns. Matern Child Health J. 2011;15(2):260-8

47. Tarrant M, Lok KYW, Fong DYT, Lee ILY, Sham A, Lam C, et al. Effect of a hospital policy of not accepting free infant formula on in-hospital formula supplementation rates and breastfeeding duration. Public Health Nutr. 2015;18(14):2689-99.

48. Tarrant M, Dodgson JE, Choi WWK. Becoming a role model: the breastfeeding trajectory of Hong Kong women breastfeeding longer than six months. Int J Nurs Stud. 2004:41(5):535-46.

49. Tarrant M, Dodgson JE, Tsang SF. Initiating and sustaining breastfeeding in Hong Kong: contextual influences on new mothers' experiences. Nurs Health Sci. 2002;4(4):189-91.

50. Tarrant M, Dodgson JE, Wu KM. Factors contributing to early breastfeeding cessation among Chinese mothers: an exploratory study. Midwifery. 2014;30(10):1088-95.

51. Tarrant M, Dodgson JE. Knowledge, attitudes, exposure, and future intentions of Hong Kong University Students toward infant feeding. JOGNN. 2007:36(3):243-54.

52. Tarrant M, Wu KM, Fong DY, Lee IL, Wong EM, Sham A, et al. Impact of baby-friendly hospital practices on breastfeeding in Hong Kong. Birth. 2011;38(3):238-45

53. Parry JE, Ip DK, Chau PY, Wu KM, Tarrant M. Predictors and consequences of in-hospital formula supplementation for healthy breastfeeding newborns. J Hum Lact. 2013;29(4):527-36.

54. Bai DL, Wu KM, Tarrant M. Association between intrapartum interventions and breastfeeding duration. J Midwifery Womens Health. 2013;58(1):25-32.

55. Bai DL, Fong DY, Tarrant M. Factors associated with breastfeeding duration and exclusivity in mothers returning to paid employment postpartum. Matern Child Health J. 2015;19(5):990-9.

56. Scott JA, Binns CW, Graham Kl, Oddy WH. Temporal changes in the determinants of breastfeeding initiation. Birth. 2006;33(1):37-45.
57. Dunn JF, Plomin R, Daniels D. Consistency and change in mothers' behavior toward young siblings. Child Dev. 1986;57(2):348-56.

58. Adams BN. Birth order: a critical review. Sociometry. 1972;35(3):411-39.

59. Jacobs BS, Moss HA. Birth order and sex of sibling as determinants of mother-infant interaction. Child Dev. 1976;47(2):315-22.

60. Lumley J, Oliver S, Waters E. Interventions for promoting smoking cessation during pregnancy. Cochrane Database Syst Rev. 1999;2:CD001055.

61. Hiscock R, Bauld L, Amos A, Fidler JA, Munafò M. Socioeconomic status and smoking: a review. Ann N Y Acad Sci. 2012;1248(1):107-23.

62. Andres RL, Day M-C. Perinatal complications associated with maternal tobacco use. Semin Neonatol. 2000;5(3):231-41.

63. England LJ, Kendrick JS, Gargiullo PM, Zahniser SC, Hannon WH. Measures of maternal tobacco exposure and infant birth weight at term. Am J Epidemiol. 2001;153(10):954-60.

64. Fantuzzi G, Aggazzotti G, Righi E, Facchinetti F, Bertucci E, Kanitz S, et al Preterm delivery and exposure to active and passive smoking during pregnancy: a case-control study from Italy. Paediatr Perinat Epidemiol. 2007;21(3):194-200.

65. American Academy of Pediatrics Committee on Drugs. The transfer of drugs and other chemicals into human milk. Pediatrics. 2001;108(3):776-89.

66. Xu F, Binns C, Yu P, Bai Y. Determinants of breastfeeding initiation in Xinjiang, PR China, 2003-2004. Acta Paediatr. 2007;96(2):257-60.

67. Chalmers B, Kaczorowski J, Darling E, Heaman M, Fell DB, O'Brien B, et al. Cesarean and vaginal birth in canadian women: a comparison of experiences. Birth. 2010;37(1):44-9.

68. Nakao Y, Moji K, Honda S, Oishi K. Initiation of breastfeeding within 120 minutes after birth is associated with breastfeeding at four months among Japanese women: a self-administered questionnaire survey. Int Breastfeed J. 2008;3:1.

69. Perez-Rios N, Ramos-Valencia G, Ortiz AP. Cesarean delivery as a barrier for breastfeeding initiation: the Puerto Rican experience. J Hum Lact. 2008;24(3):293-302.

70. Prior E, Santhakumaran S, Gale C, Philipps LH, Modi N, Hyde MJ. Breastfeeding after cesarean delivery: a systematic review and meta-analysis of world literature. Am J Clin Nutr. 2012;95(5):1113-35.

71. Chung W, Kim H, Nam C-M. Breast-feeding in South Korea: factors influencing its initiation and duration. Public Health Nutr. 2008;11(3):225-9.

72. Althabe F, Sosa C, Belizan JM, Gibbons L, Jacquerioz F, Bergel E. Cesarean section rates and maternal and neonatal mortality in low-, medium-, and high-income countries: an ecological study. Birth. 2006;33(4):270-7.

73. Hamilton BE, Martin JA, Ventura SJ. Births: preliminary data for 2010. Natl Vital Stat Rep. 2011;60(2):1-25.

74. Tang S, Li X, Wu Z. Rising cesarean delivery rate in primiparous women in urban China: evidence from three nationwide household health surveys. Am J Obstet Gynecol. 2006;195(6):1527-32.

75. Leung GM, Lam T, Thach TQ, Wan S, Ho L. Rates of cesarean births in Hong Kong: 1987-1999. Birth. 2001;28(3):166-72.

76. Montgomery A, Hale TW, Academy Of Breastfeeding Medicine Protocol C. ABM clinical protocol \#15: analgesia and anesthesia for the breastfeeding mother. Breastfeed Med. 2006;1(4):271-7.

77. Smith LJ. Impact of birthing practices on the breastfeeding dyad. J Midwifery Womens Health. 2007;52(6):621-30.

78. Thompson LA, Zhang S, Black E, Das R, Ryngaert M, Sullivan S, et al. The association of maternal pre-pregnancy body mass index with breastfeeding initiation. Matern Child Health J. 2013;17(10):1842-51.

79. Merewood A, Brooks D, Bauchner H, MacAuley L, Mehta SD. Maternal birthplace and breastfeeding initiation among term and preterm infants: a statewide assessment for Massachusetts. Pediatrics. 2006;118(4):e1048-54.

80. Pilkauskas NV. Breastfeeding initiation and duration in coresident grandparent, mother and infant households. Matern Child Health J. 2014;18(8):1955-63.

81. Anderson JW, Johnstone BM, Remley DT. Breast-feeding and cognitive development: a meta-analysis. Am J Clin Nutr. 1999;70(4):525-35.

82. Lucas A, Morley R, Cole TJ. Randomised trial of early diet in preterm babies and later intelligence quotient. BMJ. 1998;317(7171):1481-7.

83. Lucas A, Morley R, Cole TJ, Lister G, Leeson-Payne C. Breast milk and subsequent intelligence quotient in children born preterm. Lancet. 1992;339(8788):261-4.

84. Census and Statistics Department. Thematic household survey report - Report No. 53. Hong Kong: Author; 2013. 
85. Parry J. China's tainted infant formula sickens nearly 13000 babies. BMJ. 2008;337.

86. Wang J. Weaning streak. South China Morning Post. 2013 Aug 19; Sect. C:9.

87. So P. Mainlanders strain powder supply in HK. South China Morning Post [Internet]. 2008 Sep 18 [cited 2015 Oct 28]. Available from: http:// www.scmp.com/article/653044/mainlanders-strain-powder-supply-hk.

88. Hatton C. Baby milk rationing: Chinese fears spark global restrictions. In: BBC News. 2013

Submit your next manuscript to BioMed Central and take full advantage of

- Convenient online submission

- Thorough peer review

- No space constraints or color figure charges

- Immediate publication on acceptance

- Inclusion in PubMed, CAS, Scopus and Google Scholar

- Research which is freely available for redistribution 